J. Lake Sci. (湖泊科学), 2014, 26(2): 185-190

http: //www. jlakes. org. E-mail : jlakes@niglas.ac.cn

(C) 2014 by Journal of Lake Sciences

\title{
基于质量平衡的太湖氮、磷自净能力计算”
}

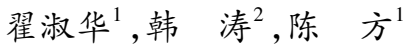 \\ $(1:$ 水利部太湖流域管理局, 上海 200434$)$ \\ (2: 中国科学院南京地理与湖泊研究所湖泊与环境国家重点实验室,南京 210008)
}

摘 要: 以太湖为研究对象, 利用 2010 年实测的进出太湖的水量和水质资料计算了太湖水体自净能力, 在分析河道人 湖、降雨、调蓄量等人湖水量水质基础上,探索了基于质量平衡原理的太湖总氮、总磷自净能力计算方法. 结果显示,通过 考虑出人湖负荷量的方法得到太湖总磷和总氮的自净率约为 $48 \%$ 和 $42 \%$, 采用基于质量平衡原理得到太湖总磷和总氮 的自净率分别约为 $52 \%$ 和 $49 \%$. 另外, 还分析了这两种方法的优缺点, 提出进一步研究太湖自净能力的工作方向.

关键词: 太湖; 氮; 磷; 自净能力; 质量平衡

\section{Self-purification capacity of nitrogen and phosphorus of Lake Taihu on the basis of mass balance}

ZHAI Shuhua ${ }^{1}$, HAN Tao $^{2} \&$ CHEN Fang ${ }^{1}$

(1: Water Resources Protection Bureau, Taihu Basin Authority, Ministry of Water Resources, Shanghai 200434, P. R. China)

(2: State Key Laboratory of Lake Science and Environment, Nanjing Institute of Geography and Limnology, Chinese Academy of Sciences, Nanjing 210008 , P. R. China)

\begin{abstract}
On the basis of mass balance and the observed data of water quantity and in the flow-in and out rivers of Lake Taihu in 2010 , the computation methods of the self-purification capacity of total phosphorus and total nitrogen of Lake Taihu are discussed. The results show that the self-purification ratio of total phosphorus and total nitrogen of Lake Taihu are about $48 \%$ and $42 \%$, respectively, with the consideration of nutrients flowing in and out of Lake Taihu. While the self-purification ratio of total phosphorus and total nitrogen of Lake Taihu are about $52 \%$ and $49 \%$, respectively, on the basis of mass balance. The merit and demerit of the two methods are figured out and prospected for further research is illustrated.
\end{abstract}

Keywords:Lake Taihu; nitrogen; phosphorus; self-purification capacity; mass balance

太湖是我国第三大淡水湖泊, 具有供水、防洪、抗旱、旅游、养殖、航运等多种功能, 1990s 以来, 伴随着太 湖流域经济的高速发展, 人湖河道水质恶化, 加之污染物直接人湖量增加, 导致太湖水质下降, 富营养化问 题突出. 2007 年太湖蓝藻暴发引发无锡供水危机后, 太湖水环境综合治理的力度进一步加大, 对太湖问题的 研究成为国家层面、国际间合作的热点和焦点. 对太湖水体自净能力以及通过水动力条件的改变对太湖自 净能力的作用进行研究, 对于富营养化湖泊治理具有重要的理论指导意义,引起了国内外不同层面的管理 人员和专家、学者的关心、关注. 国外对湖泊营养盐自净能力问题的研究较早且较深人 ${ }^{[1]}$, 美国环境保护局 于 1972 年基于水体自净能力最先提出了实际环境能够承担的最大日负荷总量 TMDL(total maximum daily loads, TMDL) 的概念. 污染排放量超过该负荷, 水环境就可能恶化, 进而对水域使用功能和生态系统产生损 伤. Vagnetti 等 ${ }^{[2]}$ 较为全面地从物理、化学和生物过程等方面,通过现场实测资料分析和历史资料的对比分 析,对不同底质下河流对氮、磷、重金属等多种污染物的自净能力进行了定量分析,得出该河流对于不同污 染物的自净量和自净能力以及主要作用因子等研究结论. 对于太湖水体自净能力的研究, 在“国家水体污染

* 水利部公益性行业科研专项项目(201101025) 资助. 2013-03-07 收稿;2013-08-30 收修改稿. 翟淑华(1964）, 女,教授级高级工程师; E-mail: Zshua@ tba. gov. cn. 
控制与治理科技重大专项” 中曾列有专题 ${ }^{[3]}$, 以太湖南部水域为对象开展了探索性研究, 研究南太湖水体自 净能力季节变化的特征, 得出影响南太湖地区小型浅水湖泊自净能力的 3 个主成分分别为浮游植物因子 (水温、 $\mathrm{pH}$ 、高锰酸盐指数和叶绿素 $\mathrm{a}$ )、农田排水因子 ( $\mathrm{pH}$ 、溶解氧和总氮) 和营养因子 (总氮和总磷).

国内专家也曾结合水环境容量研究进行过探索 ${ }^{[4-5]}$. 影响太湖自净能力的因素多样且十分复杂 ${ }^{[6]}$, 从物 理角度分析, 水流流速、流向的不同将直接对污染物迁移、扩散方向和强度带来影响, 从生物化学角度分析, 水体本身的组分决定了生物和化学进程对水域自净能力作用的大小, 如湖泊中挺水生物的多少和水质本底 浓度的高低直接影响着湖体自净能力的大小. 此外, 风对水体的强烈扰动又会增加水体中的溶解氧, 对增加 水域的自净能力有益, 在水域床底长期积累的底质污染, 即内源污染积累对水域的自净能力也有不可忽视 的间接影响. 自净能力包括了稀释、吸附、挥发、沉淀等物理自净以及氧化还原、絮凝等化学自净和生物净化 等能力. 它不是一个固定值, 而是随年度水情、水流、水质以及水生生物条件等自然环境和人类活动而变化. 随着最严格水资源管理制度的实行, 严格控制人河、湖排污总量已成为国家水资源管理的要求, 这对水域净 化能力的研究提出了更高的要求, 有必要进一步深人研究太湖水体自净能力与净化能力, 为从严核定水域 纳污容量提供理论支撑. 为此, 本文选取资料较为全面的 2010 年, 开展进出太湖的水量平衡计算和营养盐 的质量平衡计算, 通过对 2010 年太湖进出湖水量和氮、磷通量计算, 以及在进出太湖质量平衡相关要素的 资料收集和计算分析的基础上,对太湖氮、磷自净能力进行探索性量化研究.

\section{1 材料与方法}

\section{1 水量平衡要素及计算}

1.1.1 环太湖河流进出湖水量计算 太湖地处平原水网区, 水系复杂, 河道纵横交错, 出人太湖溇港河道共 计 228 条, 其中河道口门敞开的河道有 62 条. 为弄清太湖河道出人水量以及水质和掌握太湖水情及污染状 况, 国内学者展开了大量的进出太湖污染负荷通量的研究 ${ }^{[8-19]}$, 太湖流域水文部门在主要出人湖河道设置了 多个控制断面, 实施环太湖水文巡测以及资料整编, 是环湖河道通量计算的主要数据基础.

2010 年环湖出人湖河道水量数据, 采用环太湖国家水文基准站经过整编后的“2010 年环太湖水文巡测 资料”. 由于巡测线的实际工况不断变化, 2010 年湖州、苏州、无锡三市水文部门对环太湖水文巡测段进行了 新的调整: 由原来的“11 段 12 站共计 131 个进出水口门”调整为“10 段 13 站共计 130 个进出水口门”, 其中 湖州有 2 段 3 站共计 21 个进出水口门; 巡测线移至太湖边, 撤销三里桥段, 设幻溇段; 新增城北水闸站. 苏州 有 5 段 2 站共 60 个进出水口门; 巡测线移至环太湖公路,撤销五福桥段和新通安桥段,设胥江大桥段和铜坑 闸段. 无锡有 3 段 8 站共 49 个进出水口门; 撤销漕桥、黄埝桥基点站, 设浯溪桥基点站代替, 漕桥 + 黄埝桥段 改名为浯溪桥段; 浯溪桥段新增小金桥、暮渎桥、师渎桥 3 个口门; 陈东港桥段新增庙渎桥、双桥、定跨桥 3 个 口门; 另外有大港桥、雅浦桥、龚巷桥、湖山桥、大渲河原站、犊山闸、梅梁湖泵站、五里湖闸等 8 个单站.

2010 年环湖出人湖河道水量计算依据调整后的环太湖水文巡测线, 即 10 段 13 基点站共计 130 个进出 水口门(图 1) 的逐日进出湖流量. 2010 年各基点站与巡测单站水量测验频次为每天 $1 \sim 2$ 次, 在水情存在明 显变化时进行加密监测. 根据单站每日水量测验实测资料以及单站与所代表巡测段总流量的相关关系, 推 求出巡测段逐日进出太湖的水量, 据此计算得到环湖出人湖河道逐月进出湖水量和年进出湖水量. 2010 年 环太湖河流人湖水量为 $118.81 \times 10^{8} \mathrm{~m}^{3}$, 其中包括望虞河引江济太的水量, 出湖水量为 $110.06 \times 10^{8} \mathrm{~m}^{3}$.

1.1 .2 降雨量、蒸发量计算 2010 年太湖湖面降水深为 $1102.1 \mathrm{~mm}^{[7]}$, 按全年平均水位 $3.37 \mathrm{~m}$, 对应的太湖 水面面积为 $2332.75 \mathrm{~km}^{2}$, 折算为降雨量为 $25.71 \times 10^{8} \mathrm{~m}^{3}$; 湖面蒸发量为 $884.23 \mathrm{~mm}$ (湖面蒸发量采用杭长 桥、西山、瓜泾口、枫桥 4 站平均值), 按全年平均水位 $3.37 \mathrm{~m}$, 对应的太湖水面面积为 $2332.75 \mathrm{~km}^{2}$, 折算为 蒸发量为 $20.63 \times 10^{8} \mathrm{~m}^{3}$.

1.1 .3 太湖调蓄水量计算 根据“2010 年度太湖流域及东南诸河水资源公报”, 2010 年年初太湖水位为 $3.26 \mathrm{~m}$, 蓄水量为 $50.83 \times 10^{8} \mathrm{~m}^{3}$; 年末水位为 $3.10 \mathrm{~m}$, 蓄水量为 $47.17 \times 10^{8} \mathrm{~m}^{3}$; 太湖蓄变量 (蓄变量为年末 蓄水量减年初蓄水量) 为 $-3.66 \times 10^{8} \mathrm{~m}^{3}$.

1.1.4 其他水量要素计算 根据 “2010 年度太湖流域及东南诸河水资源公报”, 直接从太湖取水水量 (包括 自备水源、自来水厂等取水户)约为 $15.0 \times 10^{8} \mathrm{~m}^{3}$. 根据国务院批复的《太湖流域水资源综合规划》数据, 太 


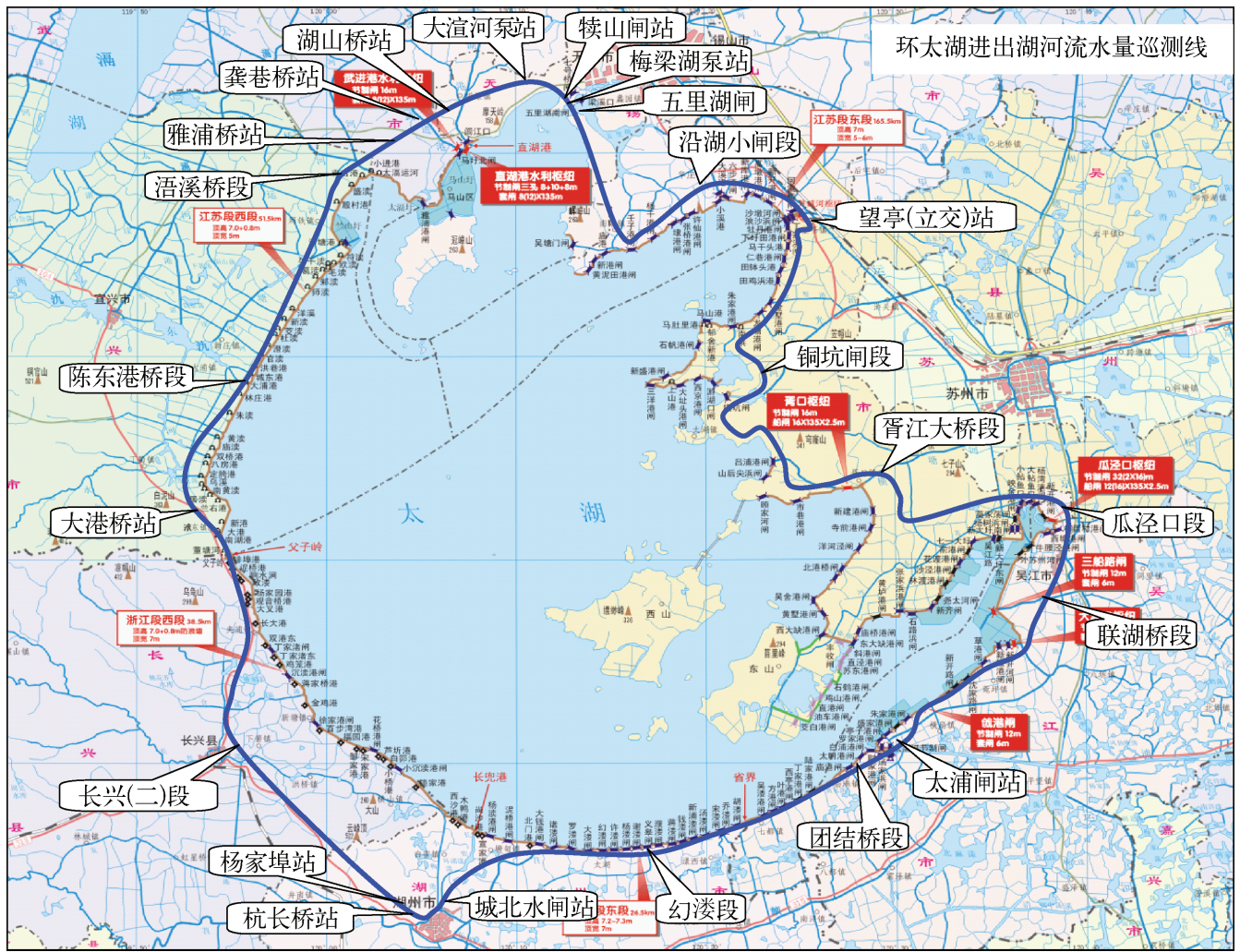

图 12010 年环太湖进出湖河流水量巡测线示意图

Fig. 1 Sketch map of hydrometric gauging line of rivers flowing in and out of Lake Taihu in 2010

湖巡测线内陆地产水模数为 $28.18 \times 10^{4} \mathrm{~m}^{3} / \mathrm{km}^{2}$, 环太湖水文巡测线所围面积为 $3454 \mathrm{~km}^{2}$, 扣除农业灌溉耗 水量 $3.40 \times 10^{8} \mathrm{~m}^{3}$, 估算得到巡测线内陆地产水人湖量约为 $0.82 \times 10^{8} \mathrm{~m}^{3}$.

1.1 .5 水量平衡计算 考虑上述各水量平衡要素, 开展对各太湖水量平衡项进行统计计算, 其计算公式为:

$$
W_{1}-W_{0}+P-E-W_{\mathrm{C}}+D \pm \Delta V=\Delta E_{1}
$$

式中, $W_{1}$ 为环太湖河流入湖水量, 根据“2010 年环太湖出水文巡测资料”逐日统计得到; $W_{0}$ 为环太湖河流出 湖水量, 根据“2010 年环太湖出水文巡测资料”逐日统计得到; $P$ 为湖面降水量, 为太湖年降水量与 2010 年 太湖平均水位对应的水面面积的乘积; $E$ 为湖面蒸发量, 为太湖年蒸发量与 2010 年太湖平均水位对应的水 面面积的乘积; $D$ 为陆地产水人湖量, 为环太湖水文巡测线范围内的陆地区域的产水人湖量; $W_{\mathrm{C}}$ 为取水户直 接取水量, 直接采用当年统计资料; $\Delta V$ 为太湖蓄变量, 为太湖年初和年末蓄水量的变化量, 当年初蓄水量大 于年末蓄水量时 $\Delta V$ 取负值, 当年初蓄水量小于年末蓄水量时 $\Delta V$ 取正值; $\Delta E_{1}$ 为水量平衡计算的绝对误差.

水量平衡计算结果显示: 2010 年太湖水量平衡人湖项 $W_{1} 、 P 、 D$ 分别为 $118.81 \times 10^{8} 、 25.71 \times 10^{8} 、 0.82 \times$ $10^{8} \mathrm{~m}^{3}$, 出湖项 $W_{0} 、 E 、 W_{\mathrm{C}}$ 分别为 $110.06 \times 10^{8} 、 20.63 \times 10^{8} 、 15 \times 10^{8} \mathrm{~m}^{3}$, 蓄变量 $\Delta V$ 为 $-3.66 \times 10^{8} \mathrm{~m}^{3}$, 水量平 衡计算的绝对误差为 $-4.01 \times 10^{8} \mathrm{~m}^{3}$, 相对误差为 $-2.8 \%$,在规范要求的误差范围以内.

\section{2 水质资料及通量计算}

1.2.1 环太湖河流水质与出入湖通量计算 水质监测资料采用太湖流域水资源保护局发布的太湖和环太湖 主要进出湖河流每月 1 次的常规水质监测资料,相关水质监测的断面布置、监测方法、监测频次以及环太湖河 道出人湖氮、磷负荷通量计算采用翟淑华等 ${ }^{[8]}$ 的方法, 即采用与水量巡测段相匹配的河流水质实测资料,计算 得到 2010 年环太湖河流人湖和出湖水量分别为 $118.81 \times 10^{8}$ 和 $110.06 \times 10^{8} \mathrm{~m}^{3}$, 带人太湖的总磷和总氮负荷 通量分别为 $0.28 \times 10^{4}$ 和 $5.64 \times 10^{4} \mathrm{t}$, 带出太湖的总磷和总氮负荷通量分别为 $0.068 \times 10^{4}$ 和 $2.54 \times 10^{4} \mathrm{t}$. 
1.2.2 降雨带入与人工带出量估算 降雨带人量为太湖湖面年降水量与其浓度之积计算得到, 其中总磷和 总氮浓度采用黄渏平 ${ }^{[9]}$ 的值. 计算得到太湖 2010 年降雨带人太湖的总氮和总磷量分别约为 2160 和 $51 \mathrm{t}$. 人 工带出太湖的总磷和总氮量主要通过取水、蓝藻打捞等生物收获资料估算, 其中水厂直接取水带出的污染 负荷量按照当年的取水量和原水水质浓度估算, 带出的总磷和总氮量分别为 76 和 $3075 \mathrm{t}$;2010 年通过蓝藻 打捞带出太湖的总磷和总氮量分别为 67 和 $335 \mathrm{t}^{[7]}$, 通过水生生物带出的总磷和总氮量参考王鸿勇等 ${ }^{[10]}$ 的 值, 约为 116 和 $3028 \mathrm{t} ; 2010$ 年底泥疏浚量为 $418 \times 10^{4}$ 方 $^{[7]}$, 依据江苏省水利厅底泥疏浚资料, $2008-2011$ 年底泥清淤工程年均疏浚 $562 \times 10^{4} \mathrm{t}$, 带出总磷和总氮分别为 725 和 $2775 \mathrm{t}$, 相应推求 2010 年底泥疏浚带出 的总磷和总氮负荷量分别约为 539 和 $2064 \mathrm{t}$; 太湖地区污染源排放的负荷量大部分主要通过河道带人太湖, 2010 年环太湖巡测线已基本调整到太湖岸边, 未调整的部分河道由于 “引江济太” 以出湖为主, 因此在太湖 污染负荷量平衡计算中,暂不考虑巡测线内污染源直接人湖量.

1.2 .3 太湖年初原有量和年末残留量计算 太湖年初原有量和年末残留量计算, 分别考虑太湖蓄水量、分区 水面积和分区水质, 其中蓄水量和分区水面积按照年初和年末水位条件下水位一库容曲线和水位面积差分 计算. 为提高湖区水质监测点的代表性, 采用泰森多边形法对太湖进行分区, 按照水质监测站点将太湖划分 为 33 个分区 (图 2).

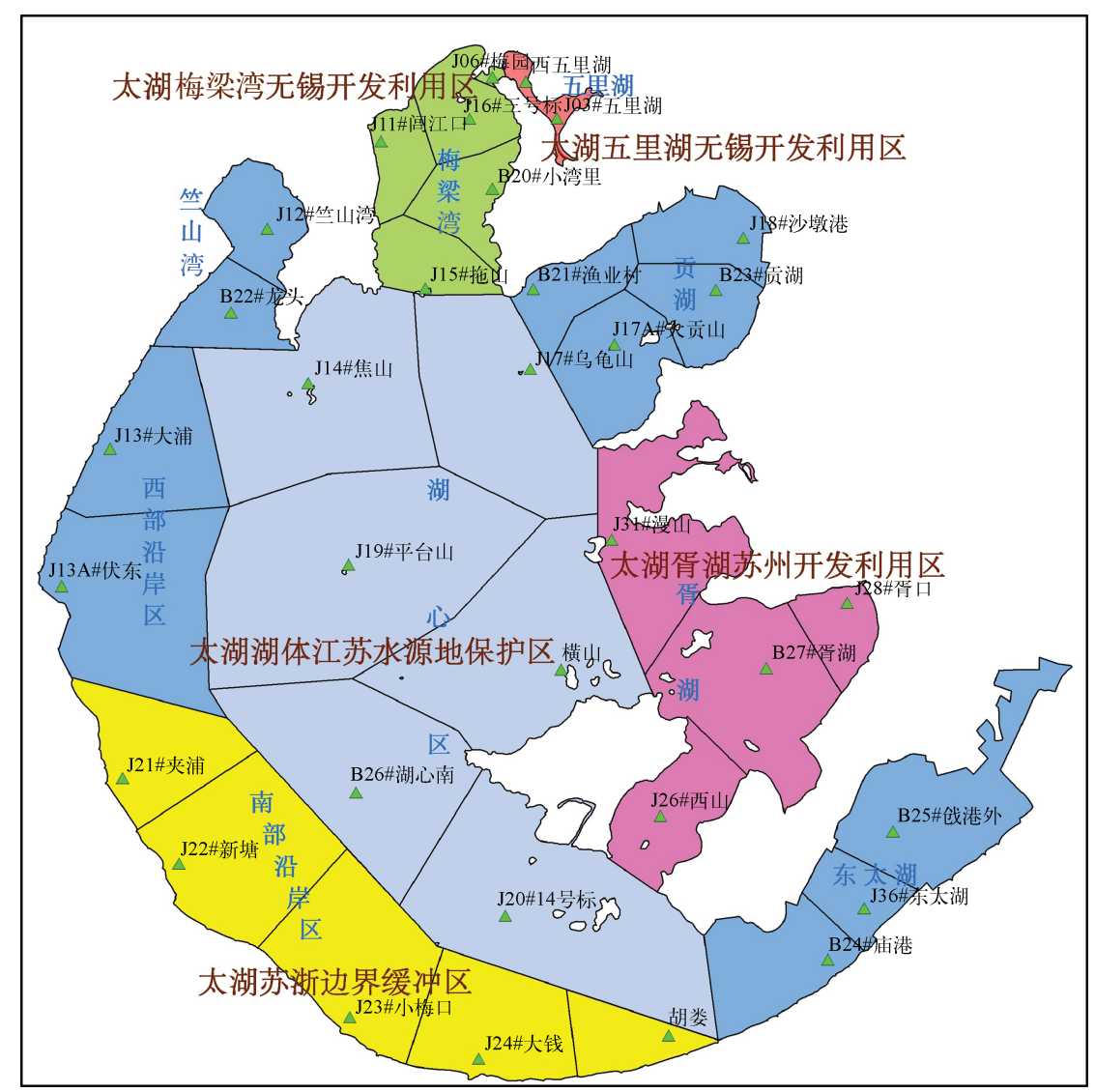

图 2 太湖湖区划分及水质代表站分布

Fig. 2 Sub zones and water quality monitoring sites in Lake Taihu

采用面积加权计算得到太湖污染负荷年初总磷和总氮原有量分别为 477.802 和 $11487.58 \mathrm{t}$, 年末残留 量分别为 297.171 和 $5566.06 \mathrm{t}$.

综上所述,得到 2010 年进出太湖氮、磷负荷通量计算结果, 详见表 1. 


\section{2 结果与讨论}

本文利用实测资料, 在上述水量平 衡、氮磷负荷通量计算的基础上, 以物质 平衡原理为基础, 在宏观层面将太湖水体 对污染物的自净过程看作一个黑箱,不论 其通过物理自净还是通过化学和生物自 净, 认为进人太湖的河流水质经过太湖水 体的自净过程后, 其自净量值即为在考虑 水量平衡误差的条件下的人湖项扣除出 湖项与水体本身含有的总量后的值. 自净 量与人湖量的比值即为自净能力. 以 2010 年总磷、总氮负荷通量计算为例, 对太湖 总磷和总氮的自净量和自净能力计算结 果进行分析及讨论.

\section{1 基于进出湖负荷通量的太湖自净能力}

采用考虑出人湖负荷量的方法进行自净能力的计算, 在不考虑太湖水体本身年初和年末调蓄量变化的 条件下,太湖氮、磷自净量的计算公式为:

$$
W_{\text {自净 }}=\left(W_{\text {人 }}+W_{\text {降雨 }}\right)-\left(W_{\text {出 }}+W_{\text {人工 }}\right)-\Delta W
$$

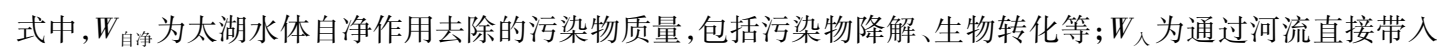

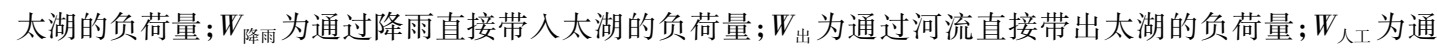
过水厂取水、蓝藻打捞和太湖底泥疏浚等途径带出太湖的负荷量; $\Delta W$ 为质量平衡计算的绝对误差.

相应地,太湖自净能力计算公式 ${ }^{[3]}$ 为:

$$
\eta=\left(Q_{\mathrm{i}}-Q_{\mathrm{o}}\right) / Q_{\mathrm{i}} \times 100 \%
$$

式中, $\eta$ 为自净能力; $Q_{\mathrm{i}}$ 为人湖污染物量, 包括人湖河流、降雨等自然输人量等,即 $Q_{\mathrm{i}}=W_{\text {人 }}+W_{\text {降雨 }} ; Q_{0}$ 包括出湖河流、直接取 水带出量、蓝藻打捞、底泥疏浚等, 即 $Q_{0}=$ $W_{\text {出 }}+W_{\text {人I }}$.

按照上述计算公式,在不考虑误差的 条件下, 即认为 $\Delta W=0$ 的条件下,计算 2010 年太湖总磷和总氮的自净率分别约

\begin{tabular}{|c|c|c|c|c|c|}
\hline \multirow{2}{*}{ 污染物 } & \multirow{2}{*}{ 自净率/\% } & \multicolumn{2}{|c|}{ 人湖负荷量 $/\left(\times 10^{4} \mathrm{t}\right)$} & \multicolumn{2}{|c|}{ 出湖负荷量 $/\left(\times 10^{4} \mathrm{t}\right)$} \\
\hline & & 河流带人 & 降雨带人 & 河流带出 & 人工带出 \\
\hline 总磷 & 48 & 0.28 & 0.005 & 0.068 & 0.082 \\
\hline 总氮 & 42 & 5.64 & 0.22 & 2.54 & 0.85 \\
\hline
\end{tabular}
为 $48 \%$ 和 $42 \%$ (表 2 ).

\section{2 基于质量平衡的自净能力计算}

由于湖泊调蓄水量和水体水质处于变化之中, 因此,湖体本身的氮、磷负荷量的变化在质量平衡中应该 予以考虑, 即在自净能力计算中考虑太湖本身水情和水质变化而产生的氮、磷年初原有量和年末残留量 ${ }^{[9]}$ 的不同. 采用质量平衡方程,计算太湖自净能力公式为:

$$
W_{\text {自净 }}=\left(W_{\text {人 }}+W_{\text {降雨 }}+W_{\text {年初 }}\right)-\left(W_{\text {出 }}+W_{\text {人工 }}+W_{\text {年末 }}\right)-\Delta W
$$

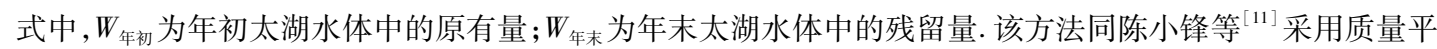
衡的方法原理一致,但增加了平衡误差项,2010 年进出太湖的水量平衡误差为 $-2.8 \%$.

相应地,太湖自净能力计算公式为:

$$
\eta=W_{\text {自净 }} /\left(W_{\text {人 }}+W_{\text {降雨 }}+W_{\text {年初 }}\right) \times 100 \%
$$

按照上述计算公式,得到 2010 年太湖总磷和总氮的自净率分别约为 52\% 和 49\% (表 3). 
表 3 采用质量平衡法计算的太湖总磷和总氮的自净能力

Tab. 3 Self-purification capacity of total phosphorus and total nitrogen in Lake Taihu on the basis of mass balance

\begin{tabular}{cccccccccc}
\hline \multirow{2}{*}{ 污染物 } & 自净率 $/ \%$ & 年初原有量 $/\left(\times 10^{4} \mathrm{t}\right)$ & 年末残留量 $/\left(\times 10^{4} \mathrm{t}\right)$ & \multicolumn{2}{c}{ 人湖负荷量 $/\left(\times 10^{4} \mathrm{t}\right)$} & & 出湖负荷量 $/\left(\times 10^{4} \mathrm{t}\right)$ \\
\hline 河流带人 & 降雨带人 & & 河流带出 & 人工带出 \\
\hline 总磷 & 52 & 0.048 & 0.030 & 0.280 & 0.005 & & 0.068 & 0.082 \\
总氮 & 49 & 1.15 & 0.56 & 5.64 & 0.22 & & 2.54 & 0.85 \\
\hline
\end{tabular}

\section{3 结论}

进出太湖的河道水质对太湖水质的影响密切相关. 本文利用已有的实测资料和相关研究数据, 以质量 平衡理论为基础, 开展了太湖氮、磷自净能力计算, 初步得出 2010 年太湖总磷、总氮的自净能力分别约为 48\% 52\% 和 42\% 49\%. 质量平衡方法建立在水量平衡和质量平衡的基础上, 理论上较为严谨, 也便于计 算, 可作为宏观上把握太湖自净能力的方法. 但由于环太湖水文巡测线不是同步监测的,在计算水量平衡时 可能会带来误差, 特别是巡测期间有降雨或人工引调水存在时影响会更大. 另外将每月 $1 \sim 2$ 次的资料作为 月平均流量也会带来误差. 为使计算结果更为准确, 需要加强进出太湖水量和营养盐监测的频度和力度, 此 外要考虑对当年资料获取的完整性.

本文提出的太湖自净能力研究方法偏于宏观, 尤其是太湖底泥带出量的计算受制于实际资料的获取, 且难以得到底泥沉降和释放过程的实际资料, 是影响自净能力估算结果精度的主要因素, 故研究太湖自净 能力作用机制更为科学的方法是采用太湖生态模型计算方法, 即利用现有的资料和对太湖水质变化的追踪 分析, 结合实际观测资料, 采用太湖生态模型对水质变化参数进行计算, 分析铵态氮、硝态氮、亚硝态氮、底 泥可交换态氮、正磷酸盐磷、底泥可交换态磷、底泥间隙水溶解性磷等不同形态营养盐转化关系, 通过太湖 水动力一生态模型探索物理、化学、生物过程对营养盐的净化作用, 定量评估在不同污染负荷压力条件下, 太湖水体不同的过程对总磷与总氮的净化能力,这将是太湖自净能力下一步研究的工作方向.

\section{4 参考文献}

[ 1 ] Benoit RJ. Self-purification in natural waters. In: Ciaccio LL ed. Water and water pollution handbook, vol. 1. New York: Dekker, 1971

[ 2 ] Vagnetti R, Miana P, Fabris M et al. Self-purification ability of a resurgence stream. Chemosphere, 2003,52(10):1781-1795.

[3] 许 否, 李 华,陈英旭等. 南太湖地区小型浅水湖泊自净能力季节变化研究. 环境科学, 2010,31(4):924-930.

[4] 范丽丽,沙海飞,逢 勇. 太湖湖体水环境容量计算. 湖泊科学,2012,24(5):693-697.

[ 5] 胡维平. 平原水网地区湖泊的水环境容量及允许负荷量. 海洋湖沼通报, 1992, (1):37-40.

[6] 何少苓,彭 静. 论提高水域纳污能力与自净能力的水动力潜力. 中国水利,2003,(1):71-73.

[ 7 ] 水利部太湖流域水资源管理局. 2010 年太湖健康状况白皮书,2010.

[8] 翟淑华,张红举. 环太湖河流进出湖水量及污染负荷 (2000-2002 年). 湖泊科学, 2006,18 (3) :225-230.

[9] 黄渏平. 太湖水环境及其污染控制. 北京:科学出版社, 2001 .

[10] 王鸿勇,张海泉,朱 喜等. 太湖蓝藻治理创新与实践. 北京: 中国水利水电出版社,2012.

[11] 陈小锋,揣小明,曾 巾等. 太湖氮素出人湖通量与自净能力研究. 环境科学, 2012,33(7):2309-2314.

[12] 燕姝雯,余 辉, 张璐璐等. 2009 年环太湖人出湖河流水量及污染负荷通量. 湖泊科学, 2011,23(6) :855-862.

[13] 郑 一, 王学军, 江耀慈. 环太湖河道水质分析与人湖污染物负荷量估算. 地理学与国土研究, 2001, 17(1):40-44.

[14] 沈国华,陈 颖. 太湖进出水量变化分析. 江苏水利,2008,(2):27-28.

[15] 戈礼宾,张泉荣,黄利亚.太湖进出水量变化及水量平衡初步分析. 江苏水利,2007,(11):33-34.

[16] 罗 缙, 逢 勇, 林 颖等. 太湖流域主要人湖河道污染物通量研究. 河海大学学报: 自然科学版, 2005,33(2): 131-135.

[17］马 倩,刘俊杰,高明远. 江苏省人太湖污染量分析 (1998-2007 年). 湖泊科学,2010,22(1):29-34.

[18] 余 辉,燕妹雯, 徐 军. 太湖出人湖河流水质多元统计分析. 长江流域资源与环境,2010,19(6):696-702.

[19] 许 梅, 任瑞丽, 刘茂松. 太湖人湖河流水质指标的年变化规律. 南京林业人学学报: 自然科学版, 2007,31(6): 121-124. 